\title{
Colonization study of antagonistic Pseudomonas sp. in Vanilla planifolia using green fluorescent protein (GFP) as a marker
}

\author{
Athul Sandheep, R., Aju K. Asok and Jisha, M.S.* \\ School of Biosciences, Mahatma Gandhi University, Priyadarshini Hills P.O. Kottayam, Kerala -686560, India.
}

Accepted 12 June, 2013

\begin{abstract}
Vanilla (Vanilla planifolia Andrews) is a high value crop cultivated for the production of Vanillin, one of the most valuable flavoring commodities in the food and beverage industry worldwide. Vanilla cultivation is severely hampered by the prevalence of various fungal diseases. Fusarium oxysporum, Rhizoctonia solani and Sclerotium rolfsii were isolated from naturally infected vanilla plants and an attempt was made to curtail the spoilage caused by the isolated fungal pathogens using biocontrol agents. Pseudomonas fluorescens P7 and Pseudomonas putida P4 were isolated from vanilla rhizosphere soil and checked for their capability to control fungal pathogens of vanilla both under In vitro and in vivo conditions. The endophytic colonisation ability of the selected rhizosphere bacteria were evaluated after genetically tagging them with a constitutively expressing green fluorescent protein gene (gfp). The green fluorescent endophytic bacteria were observed within the plant tissue when cross sections of the petiole were viewed under the confocal laser scanning microscope. The bacterial isolates were effectual in controlling the selected fungal pathogens of vanilla. The gfp- tagged Pseudomonas sp. was populated within the intercellular spaces of the vanilla leaves one week after its foliar spraying.
\end{abstract}

Key words: Biocontrol, confocal laser scanning microscope, endophytic bacteria, Fusarium oxysporum, Rhizoctonia solani, Sclerotium rolfsii.

\section{INTRODUCTION}

Vanilla (Vanilla planifolia Andrews, Syn. Vanilla fragrans saletest. Ames) is an herbaceous perennial, climbing orchid (Fa. Orchidaceae). Vanilla is the second most expensive spice after Saffron and is cultivated mainly for the production of Vanillin (4 - hydroxy3-methoxy benzaldehyde) (Walton et al., 2003), one of the most valuable flavoring commodities in the food and beverage industry worldwide (Besse et al., 2004; Divakaran et al., 2006). In India it is grown in an area of 2545 hectares covering Karnataka, Kerala and Tamilnadu with production of about 100 metric tons (Kuruvilla et al. 2004).

Vanilla cultivation is severely hindered by the incidence of various diseases. It is susceptible to many fungal diseases such as foot rot and wilting which is caused by Fusarium oxysporum and Phytophthora sp., Sclerotium rot caused by Sclerotium rolfsii, leaf rot, blights and brown spots of anthracnose caused by Colletotrichum gloeosporioides (Divakaran et al., 2008). Disease suppression by biocontrol agents is the sustained manifestation of interactions among the plant, the pathogen, the biocontrol agent, the microbial community in and around the plant and the physical environment. Inducing a plant's own defense mechanism by prior application of a biological agent is an emerging concept and strategy in plant disease management. Plant growth promoting rhizobacteria were able to colonize plant internal tissues and improve 
plant growth by applying various mechanisms including biocontrol (Pleban et al., 1995, Shishido et al., 1999). The endophytic association may provide better advantage to the host plant than the rhizosphere interaction. Confocal laser scanning microscopy (CLSM) in combination with GFP is a powerful tool for examining plant- microbe interactions. Hence in this study, to establish the ability of the rhizosphere bacteria for endophytic colonisation, the selected bacteria were tagged with green fluorescent protein and were visualised in the plant tissue using confocal laser scanning microscopy.

Plant-microbe interactions can be studied in detail with the help of tracking methods that can facilitate the visualization and localization of microbes in plant tissues. The Green Fluorescent Protein (GFP) is widely used as a reporter in studies of gene expression and protein localization in diverse organisms. Bacterial cells tagged with GFP can be enumerated in situ, and samples do not need to be disturbed by techniques such as fixing, washing, hybridization or staining (Tombolini et al., 1998). GFP, a 27 kD polypeptide (Prasher et al., 1992) which converts the blue chemiluminescence of a $\mathrm{Ca}^{2+}$ sensitive photo protein Aequorin originally descrided from the jelly fish Aequorea victoria into green light has been proved to be a simple, attractive and excellent marker system for studying plantmicrobe interaction (Chalfie et al., 1994).

The aim of this study was to establish the colonization ability of the potential biocontrol isolates in vanilla leaves and its efficiency to control phytopathogens of vanilla under green house conditions.

\section{MATERIALS AND METHODS}

\section{Isolation of Pseudomonas sp.}

Pseudomonas spp. were isolated from rhizosphere soil of vanilla plants by standard soil isolation method using King's B (KB) agar medium supplemented with nystatin. The inoculated plates were incubated at $30^{\circ} \mathrm{C}$ for $48 \mathrm{~h}$. Colonies that came up on KB plates were observed under UV light on a transilluminator. The green fluorescent colonies under UV light were picked up, purified by repeated streaking on the same medium and its morphological and biochemical characters were studied. P. fluorescens strain MTCC 1748 obtained from Microbial Culture Collection Centre Chandigarh was used as reference strain.

\section{In vitro screening of Pseudomonas spp. for their biocontrol activity}

Ten predominant rhizobacteria isolated from different locations along with standard cultures of $P$. fluorescens were tested for their antagonist effect against three fungal pathogens viz. Fusarium oxysporum, Rhizoctonia solani and Sclerotium rolfsii by dual culture method. Each fungal pathogen was grown on potato dextrose agar (PDA) plate. With the help of a sterile cork borer, a disc $(6 \mathrm{~mm})$ of fungal growth from this plate was taken and placed at one side of a fresh PDA plate. $24 \mathrm{~h}$ old culture of each bacterial strain was streaked parallel on the opposite side of the fungal disc $4 \mathrm{~cm}$ away from the disc. The plates were kept for incubation at $30^{\circ} \mathrm{C}$ for $96 \mathrm{~h}$. Visual observations on the inhibition of hyphal growth of fungal pathogens were recorded after incubation and compared with the PDA plates simultaneously inoculated with the fungal pathogens alone.

\section{Identification of selected rhizobacteria}

The selected strains were subjected to cultural, morphological, and biochemical characterization as mentioned in Bergey's Manual of Determinative Bacteriology. 16SrDNA sequencing was done and the sequences were analyzed using the gapped BLASTn (www. ncbi.nlm.nig.gov) search algorithm. The sequence generated in this study was deposited in the NCBI GenBank database.

\section{Mechanism of biocontrol activity}

A simple plate assay was performed to find out the effect of volatile compounds produced by the isolates. Fungal culture discs $(5 \mathrm{~mm})$ of F. oxysporum, $R$. solani, $S$. rolfsii were inoculated in the centre of PDA plates. The lid of fungal culture containing plates was removed and the base plate was immediately transferred to the top of the base plate containing the culture of biocontrol agents. It was then sealed tightly with parafilm and incubated for 7-8 days. Control plates with pathogen alone were also maintained. Reduction in hyphal growth of fungal pathogens was calculated.

Hydrogen cyanide production was assessed as per the method of Wei et al. (1991). All the antagonistic bacteria were inoculated in King's $\mathrm{B}$ medium and siderophore production was checked by $\mathrm{FeCl}_{3}$ test (Neilands 1981). The isolates were grown on succinate medium to test the salicylic acid production. Chitinase enzyme activity was assayed spectrophotometrically by the method suggested by Boller and Mauch (1988) using colloidal chitin as substrate. The peroxidase activity was estimated using guaiacol as substrate (Hammerschmidt et al. 1982).

Evaluation of biocontrol potential of Pseudomonas sp. against fungal pathogens of Vanilla under green house condition

A pot culture experiment was conducted to assess biocontrol potential of the isolates $P$. fluorescens and $P$. putida against fungal pathogens of vanilla by coinoculation of the pathogens and biocontrol agents (Ganesan and Gnanamanickam, 1987). For inoculum preparation, the antagonistic bacterial isolates were grown separately in Tryptic Soy Broth (TSB) and incubated at $28^{\circ} \mathrm{C}$ for three days. Bacterial cells were harvested by centrifugation $(7,000 \mathrm{rpm}$ for $20 \mathrm{~min}$ ). The pellet was washed in sterile distilled water and cells were then resuspended in sterile saline solution. The cell density was adjusted to get approximately $8 \times 10^{9} \mathrm{CFU} \mathrm{ml}^{-1}$ (Van et al., 2000).

Sporulated pure cultures of the isolated fungal pathogens, prepared on PDA medium were selected for the preparation of spore suspensions of each fungal isolate. A total volume of $20 \mathrm{ml}$ sterile water was spread in aliquots on a culture plate and the fungal colony surface was lightly scraped using a sterile spreader. The cultures were filtered through Whatman No. 42 filter paper in to a sterile glass bottle. Spore counts were taken using a haemocytometer and the suspension was adjusted to have approximately $1 \times 10^{7}$ spores $/ \mathrm{ml}$.

Three nodded vanilla cuttings were planted in unsterilized soil, sand and cow dung mixture in 1:1:1 ratio. The potting mixture was filled in $6 \times 8$ inch polybags $(1.5 \mathrm{~kg} / \mathrm{bag})$. The potting mixture without inoculation served as control. The soil had a $\mathrm{pH}$ of 7.6, 
Table 1. In vitro screening of Pseuodomonas sp. against Phytopathogens of vanilla (percentage of inhibition after 5 days).

\begin{tabular}{cccc}
\hline Biocontrol agent & Fusarium oxysporum & Rhizoctonia solani & Sclerotium rolfsii \\
\hline P1 & $38.56 \pm 0.24$ & $43.72 \pm 0.12$ & $48.62 \pm 0.29$ \\
P2 & $46.74 \pm 0.3$ & $44.47 \pm 0.47$ & $22.39 \pm 0.48$ \\
P3 & $36.28 \pm 0.5$ & $36.44 \pm 0.39$ & $47.70 \pm 0.33$ \\
P4 & $55.27 \pm 0.47$ & $57.68 \pm 0.31$ & $48.61 \pm 0.42$ \\
P5 & $43.52 \pm 0.25$ & $49.73 \pm 0.43$ & $48.60 \pm 0.47$ \\
P6 & $50.89 \pm 0.66$ & $54.51 \pm 0.38$ & $50.11 \pm 0.19$ \\
P7 & $60.93 \pm 0.21$ & $58.52 \pm 0.48$ & $54.38 \pm 0.26$ \\
P8 & $49.12 \pm 0.15$ & $56.40 \pm 0.24$ & $46.49 \pm 0.24$ \\
P9 & $45.39 \pm 0.12$ & $42.75 \pm 0.46$ & $38.38 \pm 0.24$ \\
P10 & $39.91 \pm 0.24$ & $34.22 \pm 0.34$ & $36.54 \pm 0.36$ \\
\hline
\end{tabular}

Values are average of three replications. Results represented as Mean \pm SD

$0.18 \%$ organic carbon, $0.06 \%$ of available nitrogen, $0.006 \%$ of available phosphorous and $0.012 \%$ potassium. The soil had bacterial population of $3.7 \times 10^{5} \mathrm{cfu} / \mathrm{g}$, fungi of $3.98 \times 10^{3} \mathrm{cfu} / \mathrm{g}$ and actinomycetes of $1.67 \times 10^{3} \mathrm{cfu} / \mathrm{g}$. The plants were watered twice a day to maintain optimum soil moisture regime and kept under greenhouse condition with ambient irradiance, temperature and air humidity. The pots were arranged in a completely randomised design with three replications.

Vanilla cuttings were artificially inoculated with bacterial cell

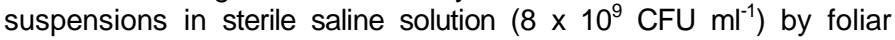
spray. Two such sprays were given in week interval as pre inoculation. One week after pre inoculations, the pathogen was given. Seven days after inoculation symptoms appeared as small lesion around the pinpricks. The appearance of visible symptoms was recorded and the severity was measured as the total number of leaves infected in all plants in each treatment. The plants were allowed to grow up to 60 days and observation on the percent leaves infection was calculated by using the formula:

Percentage of leaves infection $=\frac{\text { Number of leaves infected }}{\text { Total number of leaves }} \times 100$

\section{Transformation of the endophyte}

A portion of the freshly streaked bacterial culture was transferred to 1.5 $\mathrm{ml}$ of pre warmed C-medium using an inoculation loop. The cells were suspended by gently mixing and the tubes were incubated at $37^{\circ} \mathrm{C}$ for 2 $\mathrm{h}$ in a shaker. The bacterial cells were pelleted by centrifugation for 1 $\min$. The cells were resuspended in $300 \mu \mathrm{l}$ of T solution and incubated on ice for $5 \mathrm{~min}$. It was centrifuged for $1 \mathrm{~min}$ in a micro centrifuge and the supernatant was discarded. The pelleted cells were resuspended in $120 \mu \mathrm{l} \mathrm{T}$ solution and incubated $5 \mathrm{~min}$ on ice. $2.5 \mu \mathrm{l}$ of the ligation mixture containing $14 \mathrm{ng}$ vector DNA (pGFPuv) was taken in a new microcentrifuge tube. It was chilled on ice for $2 \min$. $50 \mu \mathrm{l}$ of the prepared cells was added to the tube containing the vector DNA and incubated for $5 \mathrm{~min}$ on ice. The cells were plated immediately on pre warmed LB-ampicillin plate $(100 \mu \mathrm{g} / \mathrm{ml})$ and incubated overnight at $37^{\circ} \mathrm{C}$. The regenerated colonies were subcultured and viewed under a UV transilluminator.

\section{Spraying of the gfp-tagged endophytes and its colonization}

Transformed colony was inoculated into TSB and incubated for $48 \mathrm{~h}$ to reach cell density of $1 \times 10^{8}$ cells $/ \mathrm{ml}$. The broth culture was diluted $1 / 5$ using sterile distilled water and sprayed on the leaves and petioles of the pot cultured cuttings of Vanilla twice with an interval of 4 days. The cuttings were uprooted and the leaves and petioles were surface sterilized using $2 \%$ sodium hypochlorite. Cross sections of the petiole was prepared and examined for fluorescence under the confocal laser scanning microscope (Leica confocal system).

The data were subjected to statistical analysis by ' $F$ ' test and the critical difference was calculated by student's 't' test at $0.05 \mathrm{P}$ level of significance (Linu et al., 2009).

\section{RESULTS}

\section{Isolation and Screening of Pseudomonas sp. against phytopathogens}

All the 10 rhizobacterial isolates of Pseudomonas sp. were tested for their biocontrol potential against three fungal pathogens and the results are presented in Table 1. The Pseudomonas sp. isolate P7 showed maximum inhibition against $F$. oxysporum $(60.93 \pm 0.21 \%) R$. solani $(58.52 \pm 0.48 \%)$ and S. rolfsii (54.38 $\pm 0.26 \%)$. The isolate P4 showed $55.27 \pm 0.4 \%$ inhibition against $F$. oxysporum, $57.68 \pm 0.31 \%$ against $R$. hizoctonia solani and $48.61 \pm 0.42 \%$ against $S$. rolfsii. These two isolates were selected for further studies.

\section{Identification of Pseudomonas sp.}

The selected isolates were was gram negative motile rods. The organism showed citrate utilization and nitrate reduction. Catalase and oxidase tests were positive. Based on the biochemical reaction, the isolate P4 was identified as 
Table 2. Growth reduction of fungal pathogens due to the organic acids produced by the isolates P.putida (P4), P. fluorescens (P7) and standard strain P. fluorescens MTCC 1748.

\begin{tabular}{llccc}
\hline \multirow{2}{*}{$\begin{array}{l}\text { Type of } \\
\text { organic acid }\end{array}$} & Fungal pathogens & \multicolumn{2}{c}{ Percentage (\%) of growth reduction } \\
\cline { 3 - 5 } & & P4 & P7 & Standard \\
\hline Volatile organic & Fusarium oxysporum & $34.48 \pm 0.6$ & $89.31 \pm 0.26$ & $58.46 \pm 0.22$ \\
acid production & Rhizoctonia solani & $31.79 \pm 0.21$ & $73.15 \pm 0.13$ & $68.45 \pm 0.12$ \\
by the isolate & Sclerotuim rolfsii & $31.10 \pm .009$ & $56.47 \pm 0.41$ & $51.83 \pm 0.09$ \\
Non volatile & Fusarium oxysporum & $34.68 \pm 0.08$ & $80.43 \pm 0.32$ & $28.45 \pm 0.22$ \\
organic acid & Rhizoctonia solani & $31.85 \pm 0.15$ & $80.33 \pm 0.23$ & $78.49 \pm 0.10$ \\
production & Sclerotuim rolfsii & $31.01 \pm 1.02$ & $69.31 \pm 0.23$ & $51.48 \pm 0.42$ \\
\hline
\end{tabular}

Values are average of three replications. Results represented as Mean \pm SD.

Pseudomonas putida and the isolate P7 was identified as Pseudomonas fluorescens.

Results of BLAST search of $16 \mathrm{~S}$ rDNA sequences of the isolate P4 showed close similarity with P. putida and the isolate P7 showed close similarity with $P$. fluorescens. The sequences of the isolated organisms were deposited in the NCBI gene bank and culture collection centre and got the accession number JF701675 for $P$. putida (P4) and JN578642 for the isolate $P$. fluorescens (P7).

\section{Mechanism of biocontrol activity}

The two selected biocontrol agents and the standard reference strain P. fluorescens (MTCC 1748) were capable of producing volatile compounds and reduced the growth of the pathogens. $P$. fluorescens showed greater inhibition against $R$. solani $(80.11 \%)$. The two isolates $\mathrm{P} 4$ and P7 were found to produce more non volatile organic compounds than the reference strains against $F$. oxysporum (Table 2).

The isolates were found to produce $\mathrm{HCN}$, siderophore and salicylic acid. The isolate P7 showed higher siderophore production compared to the isolate $\mathrm{P} 4$ and standard culture. In the case of salicylic acid production, the isolate P7 produced $0.129 \mathrm{mg}$ of salicylic acid per $50 \mathrm{ml}$ of culture whereas the isolate P4 recorded $0.089 \mathrm{mg}$ of salicylic acid production per $50 \mathrm{ml}$ of culture.

Chitinase enzyme activity was assayed spectrophotometricaly at $585 \mathrm{~nm}$. The enzyme activity of $P$. fluorescens treated plant was $3.5 \mu \mathrm{glcNAc} / \mathrm{min} / \mathrm{g}$ tissue and control (non treated plant) was $1.5 \mu \mathrm{g} \mathrm{IcNAc/min} / \mathrm{g}$ tissue. The peroxidase activity of $P$. fluorescens was estimated as 160 units/l and control showed 100 units/l after 45 days.

\section{Evaluation of biocontrol potential of isolates against fungal pathogens of vanilla under green house condition}

Visible symptoms started to appear from the fifth day after inoculation with $F$. oxysporum, $R$. solani and $S$. rolfsii in the respective control plants. The symptoms were in the form of leaf yellowing which later turned to leaf rotting. The rotting extended to leaf sheath and rarely to the pseudo stem also. Observations were recorded in terms of number of leaves infected and the severity was recorded as the total number of leaves infected in all plants in each treatment. In control plants inoculated with F. oxysporum, R. solani, and S. clerotium rolfsii alone, the infection rate was very high and severity was near $90 \%$. Besides leaf yellowing and leaf rotting, root rotting followed by wilting and dying of seedlings were also noticed. In all cases, where bioagents were inoculated first and later cross inoculated with phytopathogens, disease symptoms were not visible even after 15 to 20 days after inoculation (Table 3 ). The isolated $P$. fluorescens was found to be an efficient biocontrol agent compared to P. putida.

\section{Transformation of Pseudomonas with pGFPuv}

The antagonistic endophyte $\mathrm{P} 7$ which was identified as $P$. fluorescens was successfully transformed with pGFPuv. The transformed colonies in the LB-Ampicillin plate exhibited green fluorescence when viewed in UV light (Figure 1).

The transformed colonies were sprayed onto the leaves of the pot cultured vanilla and colonization of the isolate was confirmed by the presence of fluorescent bacteria inside the tissue when cross sections of the petiole were examined under confocal laser scanning microscope (Figure $2 \mathrm{a}$ and $2 \mathrm{~b}$ ). The bacteria were found to be localized within the intercellular spaces of the tissue

\section{DISCUSSION}

Microbial antagonists used in this study were isolated from rhizosphere soils of Vanilla. It has been suggested that microorganisms isolated from the rooted rhizosphere of a specific crop may be better adapted to that crop and may provide better control of diseases than organisms originally isolated from other plant species. Such plant 
Table 3. Evaluation of phytopathogens against microbial antagonists in vanilla plants Pre inoculation with biocontrol agent.

\begin{tabular}{cllc}
\hline Treatment & $\begin{array}{l}\text { Pre inoculation with } \\
\text { bio- control agents }\end{array}$ & Cross inoculation with pathogen & Percentage of leaves infection* $^{*}$ \\
\hline T1 & P.flourescens & Fusarium oxysporum & 7.18 \\
T2 & P.flourescens & Rhizoctonia solani & 10.31 \\
T3 & P. flourescens & Sclerotum rolfsii & 11.31 \\
T4 & P.putida & Fusarium oxysporum & 20.74 \\
T5 & P. putida & Rhizoctonia solani & 30.54 \\
T6 & P.putida & Sclerotum rolfsii & 39.17 \\
T7 & Control (no biocontrol agent) & Fusarium oxysporum & 90.27 \\
T8 & Control & Rhizoctonia solani & 93.26 \\
T9 & Control & Sclerotum rolfsii & 88.40 \\
\hline
\end{tabular}

CD $(5 \%)=1.95$. Values are mean of three replicates.

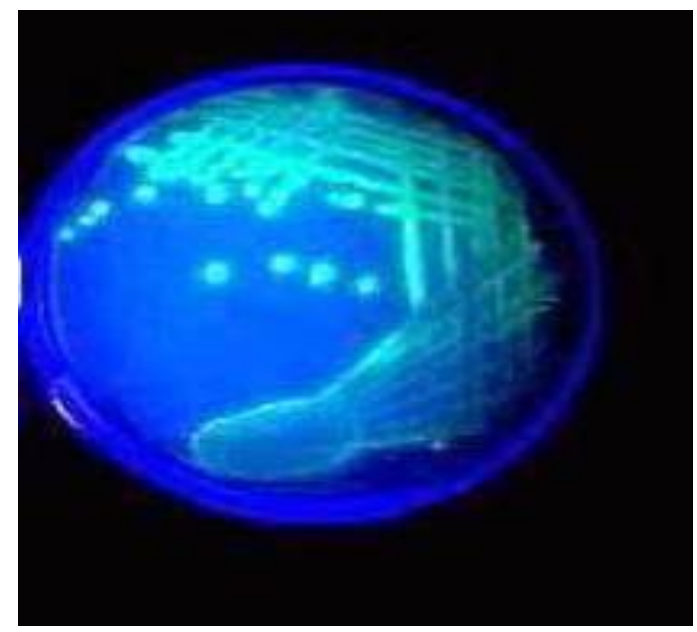

Figure 1. Transformed colonies, in the cross section of leaf, exhibiting green fluorescence.

associated microorganisms may prove to be better biocontrol agent because they are adapted to rhizosphere effect of particular plant (Srivastava et al., 2010).

$P$. fluorescens effectively suppressed the disease incidence in vanilla. These results are in line with those of Ganesan and Gnanamanickam (1987) who recorded $99 \%$ protection of groundnut plants from $S$. rolfsii infection when they were inoculated with the native strain of $P$. fluorescence under green house conditions. Bhatia et al. (2005) also noticed significant reduction in the incidence of collar rot of sunflower in S. rolfsii infested soil due to seed bacteriazation with florescent pseudo-monades.

$P$. fluorescence are known to inhibit the growth of plant pathogens by diverse mechanisms such as antibiotic production (Hill et al., 1994), siderophore production (Loper, 1988); HCN release (Voisard et al., 1989) and lytic enzyme release (Fridlender et al., 1993). Hence they have been advocated as ideal biocontrol agents and plant growth promoting rhizobacteria. Induction of resistance by $P$. fluorescens is an additional mechanism by which these bacteria protect several crop plants against pests and diseases (Anand et al., 2010). P. fluorescens used in this study were also found to produce volatile and non volatile compounds, siderophore, HCN, salicylic acid, peroxidase and chitinase enzymes which are attributed to their biocontrol efficiency

The study of localization, pattern of colonization and survival of endophytic bacteria within the plant tissue is an indispensible area of research in a scenario where endophytes have been used as biocontrol agents. The failure of many biocontrol agents is usually attributed to their inefficiency to colonize the interior of the plant .The present study employed the use of the antibiotic, rifampicin and the auto fluorescent protein, GFP to study the colonization of antagonistic endophytes. Rifampicin resistance is the most commonly used marker to study population dynamics and survival of plant growth promoting and disease suppressing Pseudomonas sp. after their introduction in plants (Bahme and Schroth, 1987).

In the present study, the most effective biocontrol agent $P$. fluorescent $\mathrm{P} 7$, which was isolated from vanilla crop, was used for transformation with pGFPuv vector. The strength of GFP as a marker lies in the detection of individual cells in a nondestructive manner. GFP expressing plasmids can be used to simplify the detection and locate the position of an individual cell on plant roots, as reported by Bloemberg et al. (1997) in their study where they observed GFP-containing cells of $P$. fluorescens WCS365.

Lagopodi et al. (2002) reported that in the interactions between the Pseudomonas biocontrol sp. (tagged with RFP) and the fungal pathogen, $F$. oxysporum (tagged with GFP); both competed for the colonization of the same niches and directly interacting each other. At sites were bacteria were present, infection of the root by penetration of Fusarium was not observed. Bloemberg et al. (1997) proved that inside the plant tissue, endophytic 

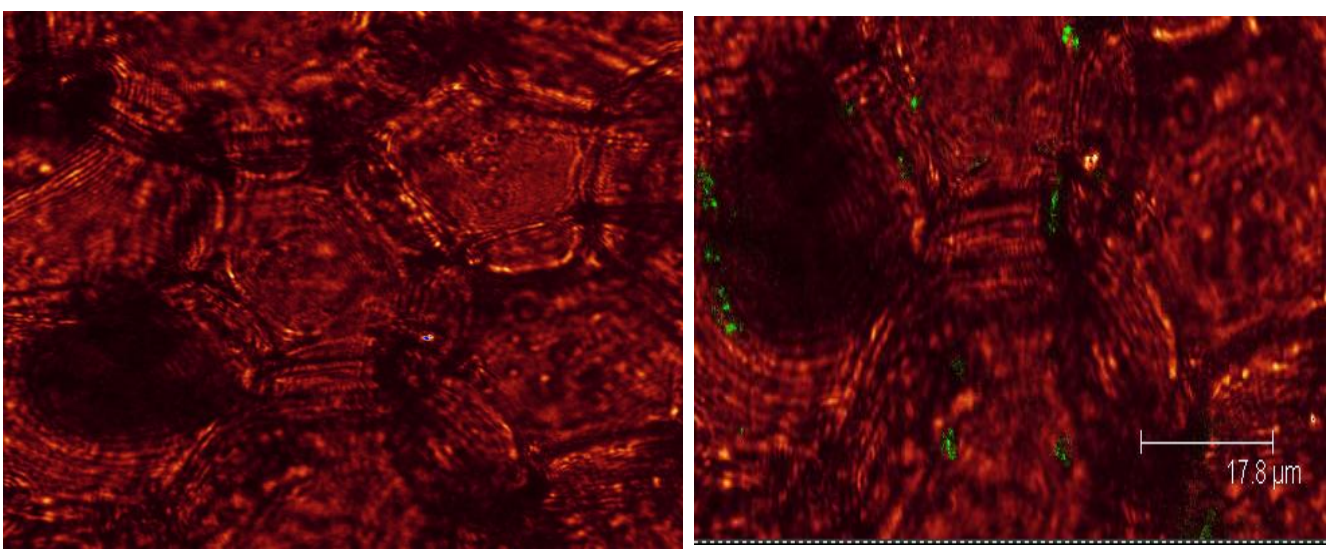

a

Figure 2a. Presence of Green fluorescence protein ( $g f p)$ - tagged bacteria in the cross sections of petiole. A, Control; $2 \mathrm{~b}, \mathrm{gfp}$ - tagged bacteria in the cross sections of petiole.

bacteria either remain localized in a specific plant tissue like the root cortex or colonize the plant systematically by transport through the conducting elements or apoplast.

This is in agreement with present study where the marked antagonistic Pseudomonas species were seen with in the vanilla leaf tissues. Advantages of the use of GFP in comparison with other reporters or dyes is that GFP is present within the cell as a product of gene expression and that the visualization does not require any fixation or preparation protocols, which may influence cellular properties. Furthermore it does not require substrates or additional energy such as often in the case of bioluminescence. Another possibility of the use of auto fluorescent proteins involve dual imaging where the fungal pathogen and the bacterial endophyte are tagged with different auto fluorescent proteins so that their interactions can be observed well.

\section{ACKNOWLEDGEMENT}

The authors are thankful to the School of Biosciences, Mahatma Gandhi University, Kottayam for the facilities provided for the present work.

\section{REFERENCES}

Anand T, Chandrasekaran A, Kuttalam S, Senthilraja G, Samiyappan R (2010). Integrated control of fruit rot and powdery mildew of chilli using the bio-control agent Pseudomonas fluorescens and a chemical fungicide. Biocontrol. 52:1-7.

Bahme JB, Schroth MN (1987). Spatial-temporal colonization pattern of a rhizobacterium on underground organs of patato. Phytopathology. 77:1093-110. Doi: 10.1094/Phyto-77-10930

Besse P, Silva DD, Bory S, Grisoni M, Bellec FL, Duval MF (2004). RAPD genetic diversity in cultivated vanilla: Vanilla planifolia, and relationships with $V$. tahitensis and $V$. pompona. Plant Science. 167: 379-385.
Bhatia S, Dubey RC, Maheshwari DK (2005). Enhancement of plant growth and suppression of collar rot of sunflower caused by $S$. rolfsii through fluorescent pseudomonads. Ind. phyto pathol. 58(1):17-24.

Bloemberg GV, O'Toole GA, Lugtenberg BJJ, Kolter R (1997). Green fluorescent protein as a marker for Pseudomonas spp. Appl. Environ. Microbiol. 63:4543-4551

Boller T, Mauch F (1988). Colorimetric assay for chitinase. Meth Enzymol. 161:430-435.

Chalfie M, Tu Y, Euskirchen G (1994). GFP as a marker for gene expression. Science. 263:802-805

Divakaran M, Babu KN, Peter KV (2006). Conservation of Vanilla species, in vitro. Sci. hortic. 110:175-180

Divakaran M, Pillai GS, Babu KN, Peter KV (2008). Isolation and fusion of protoplasts in Vanilla species. Curr. Sci. 94(1):115-120.

Fridlender M, Inbar J, Chet I (1993). Biological control of soil borne plant pathogens by a $-1,3$, glucanase- producing Pseudomonas cepacia. Soil Bio. Biochem. 25:1211-1221.

Ganesan P, Gnanamanickam SS (1987). Biological control of Sclerotium rolfsii Sacc. In peanut by inoculation with Pseudomonas fluorescens. Soil Bio. Biochem. 19(1):35-38.

Hammerschmidt R, Nuckles EM, Kuc J (1982). Association of enhanced peroxidase activity with induced systemic resistance of cucumber to Colletotrichum lagenarium. Physiol. Plant Pathol. 20:73-82.

Hill DS, Stein JI, Morse AM, Howell CR (1994). Cloning of genes involved in the synthesis of pyrrolnitrin from Pseudomonas fluorescens and role of pyrrolnitrin synthesis in biological control of plant disease. Appl. Environ. Microbiol. 60:78-85.

Kuruvilla R, Zweifel LS, Glebova NO, Lonze BE, Valdez G, Ye H, Ginty DD (2004). A neurotrophin signaling cascade coordinates sympathetic neuron development through differential control of TrkA trafficking and retrograde signaling. Cell. 118:243-255

Lagopodi AL, Ram AFJ, Lamers GEM, Punt PJ, van den Hondel CA Lugtenberg BJJ, Bloemberg GV (2002). Confocal laser scanning microscopical analysis of tomato root colonization and infection by Fusarium oxysporum f. sp. radicis-lycopersici the green fluorescent protein as a marker. Mol Plant Microbe In. 15:172-179.

Linu MS,Stephen J, Jisha MS (2009). Phosphate solubilising Gluconobactor sp. Burkholdaria sp. and their potential interaction with cowpea (Vigna unguiculata(L.) Walp.). Int. J. Agric. Res. 4(2):79-87.

Loper JE (1988). Role of fluorescent siderophore production in biocontrol of Pythium ultimum by a Pseudomonas fluorescens strain. Phytopathology. 78:166-172.

Neilands JB (1981). Microbial iron compounds. Annu Rev Biochem. 50:715-731.

Pleban S, Ingel F, Chet I (1995). Control of Rhizoctonia solani and 
Sclerotium rolfsii in the greenhouse using endophytic Bacillus spp. Eur. J. Plant Pathol. 101:665-672.

Prasher DC, Eckenrode VK, Ward WW, Prendergast FG, Cormier MJ (1992). Primary structure of the Aequorea victoria green-fluorescent protein. Gene. 111(2):229-233.

Shishido M, Colette Breuil, Christopher P, Chanway (1999). Endophytic colonization of spruce by plant growth-promoting Rhizobacteria. FEMS Microbiol. Ecol. 29:191-196

Srivastava R, Khalid A, Singh US, Sharma AK (2010). Evaluation of arbuscular mycorrhizal fungus, Pseudomonas fluorescens and Trichoderma harzianum formulation against Fusarium oxysporum $\mathrm{f}$. $\mathrm{sp}$. lycopersici for the management of tomato wilt. Bio control. 53:2431.

Tombolini R, Janson JK (1998). Monitoring of GFP- tagged bacterial cells. In: La Rossa RA (ed) Methods in molecular biology, bioluminescence methods and protocols. Humana Press Inc. Totowa, NJ. pp. 285-298.

Van VT, Berge O, Ke SN, Balandreau J, Heulin T (2000). Repeated beneficial effects of rice inoculation with a strain of Burkholderia vietnamiensis on early and late yield components in low fertility sulphate acid soils of Vietnam. Plant Soil. 218: 273-284.
Voisard C, Keel C, Haas D, Defago G (1989). Cyanide production by Pseudomonas fluorescens helps suppress black root rot of tobacco under gnotobiotic conditions. EMBO J. 8(2):351-358.

Walton NJ, Mayer MJ, Narbad A (2003). Vanillin. Phytochemistry, 63:505-515.

Wei G, Kloepper JW, Tuzun S (1991). Induction of systemic resistance of cucumber to Colletotrichum orbiculare by seven strains of plant growth promoting rhizobacteria. Phytopathology. 81:1508-1512. 